\title{
Prevalence of lactase deficiency in British adults
}

\author{
ANNE FERGUSON, DOROTHY M MACDONALD, AND W GORDON BRYDON \\ From the Gastro-Intestinal Unit, University of Edinburgh, and Western General Hospital, Edinburgh
}

SUMmaRY The prevalence of lactase deficiency in British adults is unknown. Examination of the distribution of lactase activities in single and multiple biopsies of jejunum indicated that $0.8 \mathrm{U} / \mathrm{g}$ wet weight was a suitable cut-off point to separate lactase deficient patients from others. One hundred and fifty white British adults were selected, none of whorn had significant intestinal disease and all of whom had normal histopathology of a jejunal biopsy and normal activities of other disaccharidases measured in the biopsy. The prevalence of lactase deficiency in this group was $4.7 \%$. In contrast, 15 of 20 non-white adults were lactase deficient. Lactase deficiency was found in only three of 36 patients investigated because of diarrhoea after gastric surgery, and in 16 of 200 patients with irritable bowel syndrome $(8 \%)$. As the prevalence of lactase deficiency is no higher in irritable bowel syndrome than in 'normal' individuals, lactase deficiency clearly is not a predisposing factor for irritable bowel syndrome in white British adults although the two conditions may occasionally coexist.

Mammals have a characteristic pattern of development of small intestinal lactase activity. In most species there is abundant lactase in the infant small intestine and activity declines after weaning, whether or not lactose is a constituent of the postweaning diet. ${ }^{1}$ In the human species, the postweaning reduction in intestinal lactase activity is genetically determined and although the usual condition is of adult lactase deficiency, some individuals and races have persistence of high lactase activity into adult life. ${ }^{2}$ Family studies indicate that the possession of the putative lactase persistence or lactase deficiency genes is manifest by high or low levels of tissue lactase activity in a small intestinal mucosal biopsy. ${ }^{1}$

Clinical experience suggests that lactase persistence is the usual state in British adults but there have been no formal studies of the prevalence of lactase persistence or lactase deficiency in Britain. We have identified a group of 150 essentially normal British adults, who have had a lactase assay performed in a histologically normal peroral jejunal biopsy. The prevalence of lactase deficiency in this population has been established and compared with the prevalence in two groups of patients investigated for suspected lactose intolerance - irritable bowel syndrome and diarrhoea after gastric surgery.

Address for correspondence: Dr Anne Ferguson, Gastro-Intestinal Unit, Western General Hospital, Edinburgh.

Received for publication 22 April 1983

\section{Methods}

PATIENTS AND SUBJECTS

In this gastrointestinal unit, outpatient peroral jejunal biopsies are performed by clinical investigation nurses. Many patients submitted to jejunal biopsy have, in the final analysis, no significant gastrointestinal pathology. As part of a retrospective evaluation of the indications for jejunal biopsy in clinical practice, the case notes of more than 1000 patients who had had a jejunal biopsy performed between 1976 and 1981 were scrutinised. A definitive clinical diagnosis was made, based on all the evidence available in the case notes, including jejunal biopsy histopathology but excluding the disaccharidase results. Non-British or non-white patients were recognised from the administrative details and notes in the case records. If available, information on clinical lactose intolerance was noted.

\section{JEJUNAL BIOPSY}

Single, peroral jejunal biopsies were performed with a Watson capsule, radiographic screening being used to identify the location of the capsule at the time of firing (within $20 \mathrm{~cm}$ of the ligament of Treitz). In a few patients who had previous gastric surgery, jejunal biopsies were taken under direct vision at upper gastrointestinal endoscopy. Biopsies were taken at least $10 \mathrm{~cm}$ distal to a gastrojejunal 
anastomosis, from the efferent loop of jejunum. In 14 patients, multiple biopsies of the proximal jejunum were taken with the Quinton hydraulic multiple biopsy apparatus.

\section{HISTOPATHOLOGY}

Part of each biopsy was formalin fixed, paraffin embedded, and processed for routine diagnostic pathological exmination. In addition to a formal report by a clinical pathologist, all slides were independently reviewed. Patients were included in this study only if there was agreement that histopathology was absolutely normal. Features examined included relative sizes of villi and crypts, morphology of enterocytes, lamina propria and intraepithelial lymphoid cell infiltrates.

DISACCHARIDASE ASSAY

The other part of each biopsy was used for assay of disaccharidases by Dahlqvist's method; ${ }^{3}$ lactase, sucrase, and trehalase or maltase were measured. Patients were only included in the study if the activities of other disaccharidases were within a previously established normal range ${ }^{4}$ - that is, if sucrase activity was greater than $2.5 \mathrm{U} / \mathrm{g}$ wet weight, trehalase activity above $0.9 \mathrm{U} / \mathrm{g}$, and maltase above $9 \mathrm{U} / \mathrm{g}$.

\section{Results}

VALIDITY OF LACTASE ASSAY IN A SINGLE PERORAL JEJUNAL BIOPSY

Variability

In order to measure day to day variability in the routine laboratory assay technique for lactase, a single specimen was processed along with diagnostic biopsies on nine separate occasions. Values obtained ranged from 6.2 to $8.3 \mathrm{U} / \mathrm{g}$ wet weight, mean 7.05 , standard deviation 0.88 . The coefficient of variation for the method was therefore $12.6 \%$.

\section{Multiple biopsies}

The presence or absence of patchiness for lactase activities in the proximal jejunum was evaluated in a group of 14 patients submitted to multiple jejunal biopsies. All had normal histopathology and normal activities of other disaccharidases and the diagnoses are listed in Table 1. Between three and seven biopsies were examined from each patient and results of lactase assays are illustrated in Figure 1. The three patients with clinical lactose intolerance all had low lactase activities (below $0.8 \mathrm{U} / \mathrm{g}$ ). Only one of the 69 multiple biopsies from lactose tolerant subjects had a value below this level but in general, there was a fairly wide scatter of values for lactase activity in these tissues with up to three-fold
Table 1 Final diagnosis in patients submitted to multiple jejunal biopsy

\begin{tabular}{ll}
$\begin{array}{l}\text { Case } \\
\text { number }\end{array}$ & Diagnosis \\
\hline $1-5$ & $\begin{array}{l}\text { Idiopathic diarrhoea (irritable bowel syndrome) } \\
\text { Normal, previously diagnosed as coeliac disease; } \\
\text { multiple biopsies carried out one year after gluten } \\
\text { reintroduction; biopsy remains normal more than } \\
\text { two years after gluten reintroduction }\end{array}$ \\
10 & $\begin{array}{l}\text { Hypogammaglobulinaemia with diarrhoea } \\
\text { Previous gastrectomy and abdominal radiotherapy for } \\
\text { lymphoma }\end{array}$ \\
11 & $\begin{array}{l}\text { Diarrhoea after abdominal radiotherapy for seminoma. } \\
\text { Lactose intolerant } \\
\text { Relative of coeliac; diarrhoea; lactose intolerant } \\
\text { Asian; former resident in Tropics; lactose intolerant; } \\
\text { irritable bowel syndrome }\end{array}$ \\
\hline
\end{tabular}

variation between the values for the highest and lowest tissue lactase measurement within the same patient.

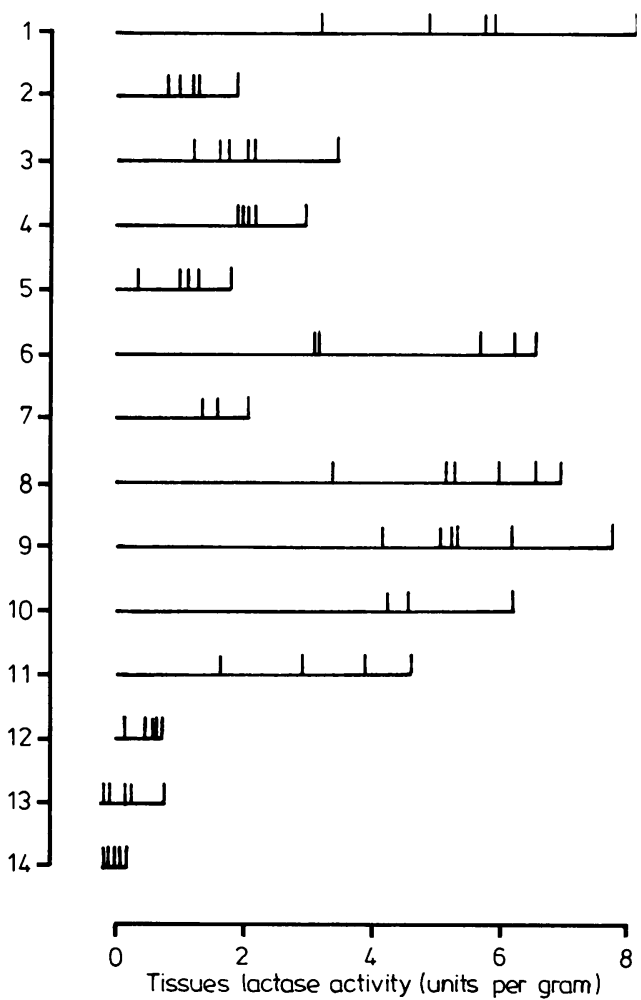

Fig. 1 Tissue lactase activity in multiple biopsies of proximal jejunum from 14 patients. (In patients 13 and 14, values apparently below zero indicate more than one biopsy with lactase activity of $0 \cdot 0$.) 
LACTASE IN 'NORMAL' WHITE BRITISH ADULTS There were 150 patients who fulfilled the criteria for inclusion in a group of 'normal' adults. They were white British subjects, taking a normal diet. There was no significant intestinal disease, and jejunal biopsy histopathology and activities of other disaccharidases were normal. The categories are listed in Table 2 and the distribution of tissue lactase activities in these 150 patients is illustrated in the top section of Figure 2. Direct inspection clearly shows a group of patients who have low levels of lactase activity $(<0.6 \mathrm{U} / \mathrm{g})$ contrasted with the vast majority who have substantial activity ranging from 0.9 to 9.2 $\mathrm{U} / \mathrm{g}$. The distribution of low lactase values in the different patient categories is documented in Table 2.

\section{LACTASE IN NON-WHITE PATIENTS}

There were 20 patients who were Indian, Chinese, Negro, or Arab, and who had had a jejunal biopsy performed as part of an investigation of gastrointestinal symptoms in order to define whether or not lactase deficiency was present. Of these, 15 of 20 had low lactase activity (Fig. 2).

\section{LACTASE IN SYMPTOMATIC PATIENTS}

As illustrated in Figure 2, only 16 of 200 patients investigated because of irritable bowel syndrome, and three of 36 who had significant diarrhoea after gastric surgery (vagotomy or gastrectomy) had lactase deficiency. In neither of these was the prevalence significantly higher than in the group of normal British adults. Jejunal biopsy is not performed routinely in all irritable bowel syndrome patients in this Unit, and the 200 patients concerned had, usually, clinical features such as complaints of flatus or diarrhoea, which were compatible with the presence of small bowel disease or lactose intolerance.
Although this retrospective analysis of case records did not incorporate a formal assessment of lactose intolerance in the patients, it was clear from perusal of the notes that all three lactase deficient postgastric surgery patients had overt clinical lactose intolerance and responded well to a low lactose diet whereas clinically relevant lactose intolerance was unusual in the group of patients with irritable bowel syndrome.

\section{Discussion}

There are differences in lactase activity within the brush border of a single enterocyte at different phases of its lifespan, in enterocytes of different segments of the small intestine, and in the intestine of a single individual at different ages from infancy to adult life. ${ }^{5-7}$ Variation also occurs between populations and the nature of natural selection leading to lactase persistence or lactase deficiency in adult life has been the subject of considerable debate. Clinically, the existence of lactase deficiency in adults is important as adverse symptoms are precipitated in some $50 \%$ of lactase deficient adults on ingestion of a single glass of milk $^{8}$ and lactose intolerant adults drink less cows' milk than do those who are lactose tolerant. ${ }^{9}$ As the clinical features of lactose intolerance - abdominal pain, diarrhoea, flatus - are similar to those of the irritable bowel syndrome, lactose intolerance is frequently cited as one of the causes of this condition ${ }^{10} 11$ and of the analogous syndrome in childhood, idiopathic abdominal pain. ${ }^{12}$ Lactose intolerance is an important, treatable, although rare cause of diarrhoea after gastric surgery. ${ }^{13}$ Nevertheless, in contrast with these syndromes in adults, by far the clinically most important type of lactose intolerance is the transient state which occurs in infants and young children, secondary to intestinal infections

Table 2 Details of 'normal' white British adults

\begin{tabular}{|c|c|c|c|c|c|c|c|}
\hline \multirow[b]{2}{*}{ Clinical category } & \multirow{2}{*}{$\begin{array}{l}\text { Patients } \\
\text { (no) }\end{array}$} & \multicolumn{6}{|c|}{ Tissue lactase activity $(\mathrm{U} / \mathrm{g})$} \\
\hline & & 0.0 & $-0 \cdot 2$ & -0.4 & -0.6 & $-0 \cdot 8$ & $\geqslant 0 \cdot 81$ \\
\hline \multicolumn{7}{|l|}{ Normal (volunteers for research studies; normal } & 25 \\
\hline Aphthous ulcers (research study) & 32 & & & & 1 & & 31 \\
\hline $\begin{array}{l}\text { Haematological (nutritional iron or folate deficiency, } \\
\text { biopsy performed after haematinic treatment) }\end{array}$ & 35 & 1 & & 1 & & & 33 \\
\hline Alcohol related symptoms (vomiting, macrocytosis) & 12 & 1 & & & & & 11 \\
\hline $\begin{array}{l}\text { Psychiatric (definitive psychiatric diagnosis made, } \\
\text { which explained gastrointestinal symptoms) }\end{array}$ & 23 & & & 1 & & & 22 \\
\hline $\begin{array}{l}\text { Miscellaneous (trivial gastrointestinal symptoms or } \\
\text { disorders unrelated to the small intestine - for } \\
\text { example, oesophagitis, haemorrhoids) }\end{array}$ & 22 & 1 & & & & & 21 \\
\hline
\end{tabular}


Fig. 2 Distribution of tissue lactase activities in peroral biopsies of proximal jejunum from 150 'normal' white British adults, 20 non-white patients, 200 white patients with irritable bowel syndrome, and 36 white patients who complained of diarrhoea after gastric surgery. Bars indicate biopsies in which lactase activities were in range 0.0 to $0.40 ; 0.41$ to $0.80 ; 0.81$ to 1.20 etc.

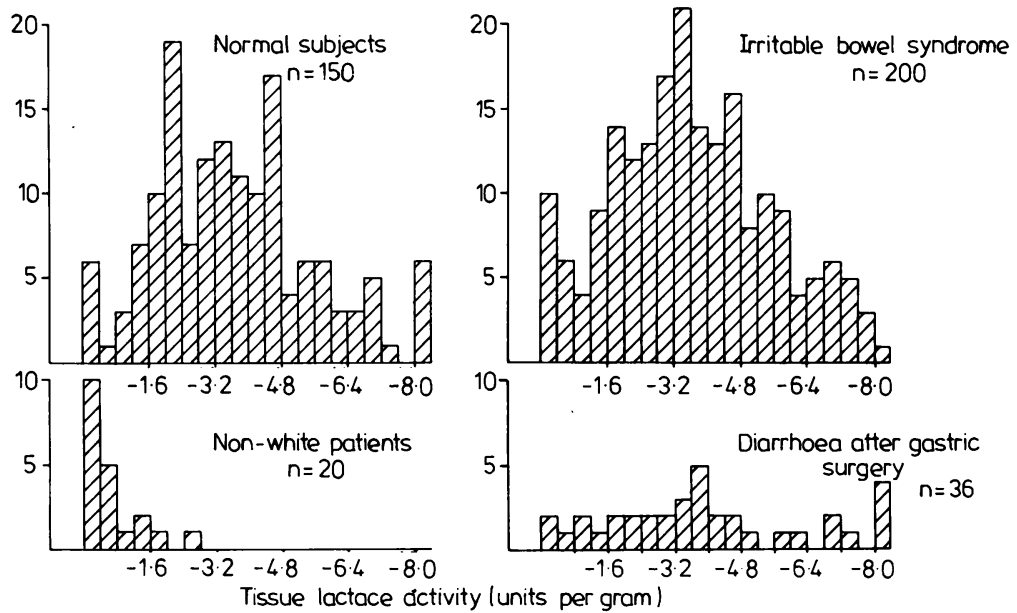

and other inflammatory states. ${ }^{14}$ In order firmly to exclude transient lactase deficiency, it was important that the subjects selected for this study had no evidence of other small bowel disease and had unequivocally normal intestinal histopathology. Lactase activity of $0.8 \mathrm{U} / \mathrm{g}$ jejunal tissue was taken, arbitrarily, as a level below which patients were classified as lactase deficient. This value was selected by inspection of patterns of results in white and non-white subjects, and in the multiple jejunal biopsy study. In the only other similar paper in the literature, a value of $0.6 \mathrm{U} / \mathrm{g}$ was chosen, again arbitrarily from direct inspection of the data. ${ }^{15}$

The prevalence of lactase deficiency in apparently normal white British adults has been found to be $4.7 \%$. This is similar to the value of $5 \%$ which is often cited as the prevalence in Britain, based on a note in the discussion of the classic paper on lactase deficiency in the irritable bowel syndrome by Peña and Truelove. They gave no details of how they arrived at this figure, however. ${ }^{16}$

Although the symptoms of irritable bowel syndrome are very similar to those of lactose intolerance it is clear from the results presented in this paper that even when patients with irritable bowel syndrome have symptoms of sufficient severity and type to merit investigation of small bowel structure and function, the proportion with lactase deficiency is not significantly higher than in the normal population. These results relate to white British (mainly Scottish) adults. It remains to be shown whether clinical investigation of irritable bowel syndrome patients of other races would be more fruitful. Our results suggest that in the clinical investigation of patients with either irritable bowel syndrome or diarrhoea after gastric surgery, observation of the clinical effects of a lactose load should be the procedure of choice if lactose intolerance is suspected; if clinical effects are produced by this manoeuvre, it would then be appropriate further to investigate the patient by biopsy, disaccharidase assay, and/or breath hydrogen tests. These can differentiate the permanent primary adult lactase deficiency from reversible post-enteritis enteropathy associated with lactose intolerance.

We are grateful to the other consultants of the Gastro-Intestinal Unit who have given permission to study their patients; and acknowledge the skills and painstaking patient care of the nursing staff of the Clinical Investigation Area. Jejunal biopsy histopathology has been reported by Drs $\mathrm{M}$ Drennan, $\mathrm{N}$ Maclean, J Webb, A Busuttil, and M McIntyre, and we continue to value their clinical and research collaboration. We thank Drs $R$ Logan and $P$ Earnshaw who performed the multiple jejunal biopsy procedures. This work has been supported by a grant from the Lothian Health Board.

\section{References}

1 Johnson JD. The regional and ethnic distribution of lactose malabsorption. Adaptive and genetic hypotheses. In: Paige DM, Bayless TM, eds. Lactose digestion. Baltimore: Johns Hopkins University Press, 1981: 11-22.

2 Simoons FJ. Primary adult lactose intolerance and the milking habit: a problem in biological and cultural 
interrelations. II. A cultural historical hypothesis. Am J Dig Dis 1970; 15: 695-710.

3 Dahlqvist A. Method for assay of intestinal disaccharidases. Anal Biochem 1964; 7: 18-25.

4 Paton E, Murray ES, Watson WC. Intestinal disaccharidase activity in rosacea. $\mathrm{Br}$ Med $J$ 1966; 1 : 459-60.

5 Nordstrom C, Dahlqvist A. Quantitative distribution of some enzymes along the villi and crypts of human small intestine. Scand J Gastroenterol 1973; 8: 407-16.

6 Gray GM. Carbohydrate digestion and absorption. $N$ Engl J Med 1975; 292: 1225-30.

7 Simoons FJ, Johnson JD, Kretchmer N. Perspective on milk-drinking and malabsorption of lactose. Paediatrics 1977; 59: 98-109.

8 Bayless TM, Rothfield B, Massa C, Wise L, Paige D, Bedine MS. Lactose and milk intolerance: clinical implications. N Engl J Med 1975; 292: 1156-9.

9 Fowkes G, Ferguson A. Prevalence of self-diagnosed irritable bowel syndrome and cows' milk intolerance in white and non-white doctors. Scott Med J 1980; 26: 41-4.

10 Anonymous. Lactose malabsorption and lactose intolerance. [Leading article.] Lancet 1979; 2: 831-2.

11 Ferguson A. Diagnosis and treatment of lactose intolerance. Br Med J 1981; 283: 1423-4.

12 Barr RG, Levine MD, Watkins JB. Recurrent abdominal pain of childhood due to lactose intolerance. A prospective study. N Engl J Med 1979; 300: $1449-52$.

13 Gudmand-Hoyer E, Jarnum S. Milk intolerance following gastric surgery. Scand J Gastroenterol 1969; 4: $127-32$.

14 Walker-Smith JA. Diseases of the small intestine in childhood. Tunbridge Wells: Pitman, 1979: 250-78.

15 Newcomer AD, McGill DB. Disaccharidase activity in the small intestine. Prevalance of lactase deficiency in 100 healthy subjects. Gastroenterology 1967; 53: 881-9.

16 Peña AS, Truelove SC. Hypolactasia and the irritable colon syndrome. Scand J Gastroenterol 1972; 7: 433-8. 